UCRL. 95962

PREPRIVI

\title{
HYDROGEN SPECIATION IN HYDRATED LAYERS ON NUCLEAR WASTE GLASS
}

\author{
Roger D. Aines \\ Homer $C$. Weed \\ John K. Bates* \\ *Argonne National Laboratory
}

This paper was prepared for submittal to Materials Research Society Symposium on the Scientific Basis for Nuclear Waste Management Boston, MA, December 1-6, 1986

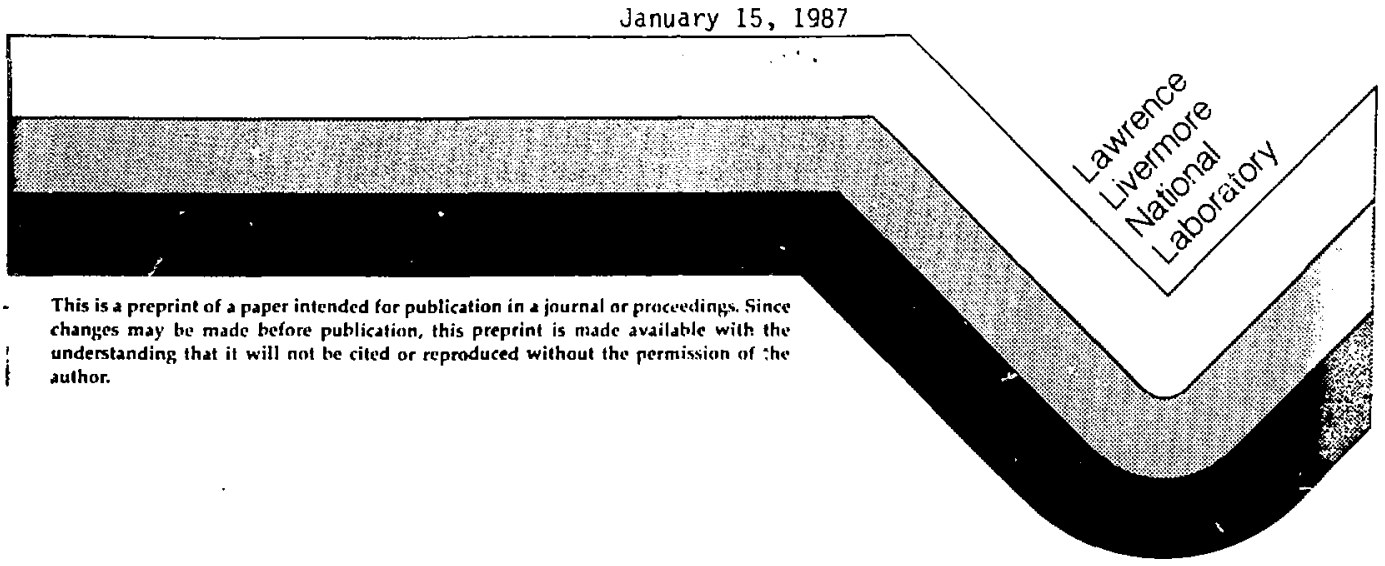


ROGER D. AINES*, HOMER C. WEED*, AND JOHN K. BATES**

- Lawrence Livermare National Laboratory, Earth Sciences Department. P.0 Box 808, L-202, Livermore, CA 94550

* Argonne National Laboratory, Chemical Technology Division, 9700

S. Cass Avenue, Argonne, Illinois, 60439

ABSTRACT

UCRL--95962

\section{ABSTRACT}

The hydration of an outer layer on nuclear waste glasses is known to occur during leaching, but the actual speciation of hydrogen (as water or hydroxyl groups) in these layers has not been determined. As part of the Nevada Muclear Waste Storage Investigations Project, we have used infrared spectroscopy to determine hydrogen speciations $n$ three nuclear waste glass compositions (SRL-131 \& 165, and PNL 76-6), which were leached at $90^{\circ} \mathrm{C}$ (all glasses) or hydrated in a vapor-satu ated atmosphere at $202^{\circ} \mathrm{C}$ (SRL-131 on $1 y$ ). Hydroxyl groups were found in the surface layers of all the glasses. In addition, molecular wat $r$ was found in the surface of SRL-131 and PNL 76-68 giasses that had Leen leached for several months in delonized water, and in the vapor-hydrated sample. The water/hydroxyl ratio increases with increasing reaction time; molecular water makes up most of the hydrogen in the thick reaction layers on vapor-phase hydrated glass while only hydroxyl occurs in the least reacted samples. Using the known molar absorptivitie: of water and hydroxyl in silica-rich glass the vapor-phase layer cont ined 4.8 moles/liter of molecular water, and 0.6 moles water in the forr hydroxyl. A 15 micrometer layer on SRL-131 glass formed by leachir? at $90^{\circ} \mathrm{C}$ contained a total of 4.9 moles $/ 1$ iter of water, $2 / 3$ of which wa: as hydroxyl. The unreacted bulk glass contains about 0.018 moles $/ 1$ iter water, all as hydroxyl.

The amount of hydrogen added to the SRL-131 glass was about $70 \%$ of the original $\mathrm{Na}+\mathrm{Li}$ content, not the $300 \%$ that would result from alkallahydrontum ion $\left(\mathrm{H}_{3} \mathrm{O}^{+}\right)$interdiffusion. If all the hydrogen is then assumed to be added as the result of alkali-H+ interdiffusion. the molecular water observed may have formed from condensation of the original hydroxyl groups according to:

$$
2 \mathrm{OH}=\mathrm{H}_{2} \mathrm{O} \text { molecular }+\mathrm{OO}^{\circ}
$$

where $0^{0}$ refers to a bridging oxygen, and $0 H$ refers to a hydroxyl group attached to a silicate polymer. The hydrated layer on the nuclear waste glasses appears to be of relatively low water content (4 to $7 \%$ by weight) and is not substantially hydroxylated. Thus, these layers do not have many of the properties associated with "gel" Iayers.

\section{INTRODUCTION}

The concept of a "gel" layer forming on nuclear waste glass after reaction with water has been broadly accepted (e.g. [1]), and is an important part of discussions of kaste glass leaching presented in several other papers in this symposium $[2,3]$. The gel layer is widely belfeved to be hydrated, of low density, and depleted in soluble components, particularly alkalis. The depletion in alkalis is thoud to occur through exchange of hydrogen from solution. If this were tif complex such as $\mathrm{H}_{3} \mathrm{O}^{+}$, the gel layer would contain only hydroxide, 
and at the same concentrations as the original alkali elements. In this paper we discuss the speciation of hydrogen in the gel layer, as determined by infrared (IR) spectroscopy. This work was conducted as part of glass waste form testing (Waste Package task) for the Nevadz Nuclear Waste Storage Investigations project.

\section{EXPERIMENTAL}

The speclation of hydrogen in glasses and silicate solids may be readily determined by infrared spectroscopy [e.g. 4-9]. Figure i shows a typical spectrum for a hydrated silica-rich giass, in the regions. providing the most information about hydrogen speciation. The absorptions at $4300-4600$ and $5200 \mathrm{~cm}^{-1}$ are the most useful in determining hydrogen speciation, as they are uniquely due to hydroxyl and water, respectively. The exact location of the hydroxyl absorption varies slightly as a function of its local environment [4]. The absorptions at $3500 \mathrm{~cm}^{-1}$ are intense (Figure 2), and are useful in determining total water content (irrespective of speciation) in relatively dry glasses where the near-infrared absorptions are not intense enough to use quantitatively. The absorption at $1620 \mathrm{~cm}^{-1}$ due to molecular water requires care in use, because of underlying absorptions due to the anhydrous glass.

Infrared spectra presented in this paper were obtained using a Nicolet 60SX. Fourler transform infrared spectrometer. With a $\mathrm{Hg}-\mathrm{Cd}-\mathrm{Te}$ Liquid $\mathrm{H}_{2}$ cooled detector and a $\mathrm{KBr}$ beansplitter. Transmission spectra were obtained in the normal sample compartment, and in a highly-focused ( $f 1.0$ ) microbeam compartment. Stainless steel apertures were placed in contact with the samples to restrict light to only the region desired. Spectra were also obtained by diffuse reflectance using the Barnes-Nicolet diffuse reflectance apparatus, with an aluminum surface-coated mirror as the reference. In this technique, parabolic mirrors focus and re-collect reflected $11 \mathrm{ght}$ from a large solid angle

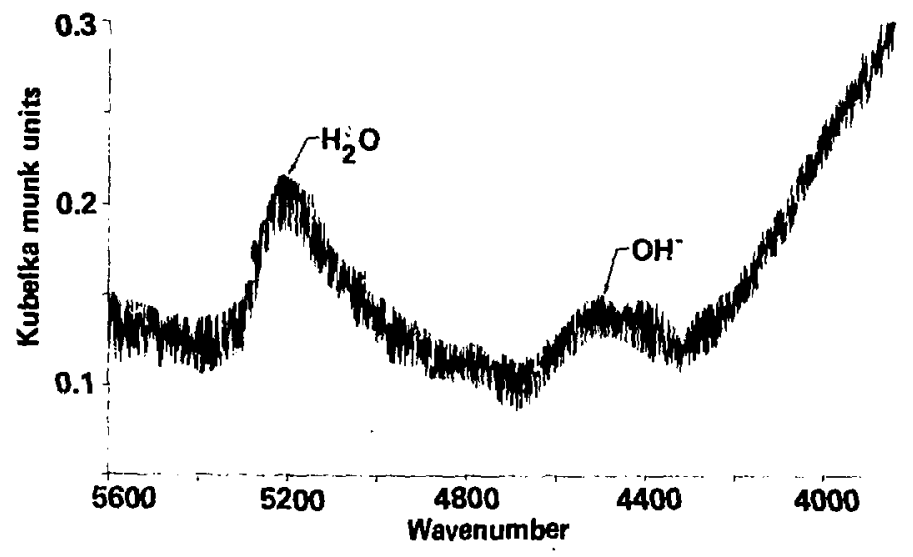

Figure 1. Near-Infrared spectrum of hydrated ATM $1-c$ glass. The absorption at $4500 \mathrm{~cm}^{-1}$ is assigned to combined oxygen-hydrogen stretch and wagging of hydroxyl (X-OH); the absorption at $5200 \mathrm{~cm}^{-1}$ to combined stretching and scissoring of molecular vater. Diffuse reflectance un powder, reacted in DIN 28 days S/V $=4 / \mathrm{Cm}$ at $90^{\circ} \mathrm{C}$. 


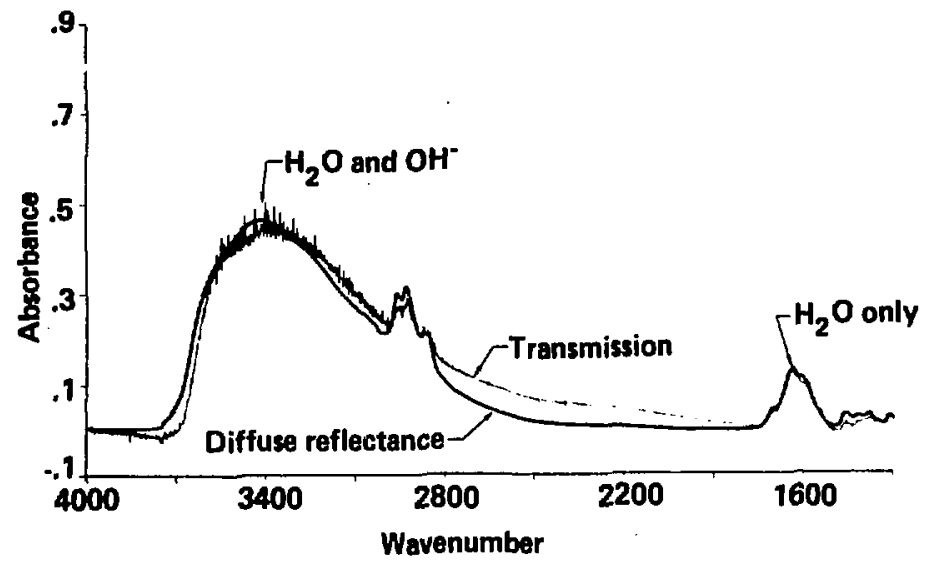

Figure 2. Comparison of the infrared transmisston and diffuse reflectance spectra of a thin flake of a hydrated layer from SRL-131 glass, hydrated in DIK under MCC-l conditions $\left(90^{\circ} \mathrm{C}, S / V=0.1 / \mathrm{cm}\right)$ for 183 days. The absorption at $1620 \mathrm{~cm}^{-1}$ is assigned to the scissor (bending) motion of molecular water; the absorption at $3500 \mathrm{~cm}^{-1}$ to oxygen-hydrogen stretching in both hydroxyl and molecular water. Light path was parallel to the layer growth direction, thickness $15 \mu \mathrm{m}$. Kubelka Munk data have been scaled to match the intensity of the absorbance data at $3500 \mathrm{~cm}^{-1}$; Kubelka Munk intensity was 2.3 units.

[10]. Diffuse reflectance spectra are reported in Kubelka-Munk units (inversely proportional to the square of the reflected light intensity) which are proportional to the amount of absorbing species in a simt lar. but less rigorous, fashion as the Beer-Lambert law for transmission [10]. Glass samples used for both methods are held in a dry $\mathrm{N}_{2}$ atmosphere during the measurement and are never subjected to vacuum. Similar samples subjected to high vacuum during nuclear reaction analys is [2] show minor dehydration. This suggests that our samples have not dehydrated signiflcantiy, but we cannot rule out some water loss.

Transmission spectra have been shown to provide quantitative Information on both hydrogen speciation and concentration in glasses [5-9]. However, most hydrated layers are too thin to separate for transmission analysis. Diffuse reflectance has the advantage of requiring no sample preparation. Diffuse reflectance spectra have not prevlously been used for quantitative measurements because the path length through the sample is poorly constrained due to surface trregularities. Absolute measurements of the resuiting absorption in diffuse reflectance are not used in this paper. However, in a single sample the light path is simflar for all infrared and near-infrared wavelengths, leading to the possiblifity that in a single sample the relative peak heights of the absorptions shown in Figure 1 will be quantitatively maintained. Two tests of this were made. In the first (FIg. 2), the quantitative IR transmission spectrum of a separated 15 m thick flake from a hydrated layer was compared to the diffuse refiectance spectrum of the same sample. The relative peak heights in 
the infrared region were maintained within experimental error. Thus, diffuse reflectance may be used to determine water/hydroxyl ratios in hydrated layers.

In a second test of diffuse reflectance, natural hydrous obsidian samples previously studied [9] by transmission spectroscopy and hydrogen manometry were used. These samples, unlike the reacted nuclear waste glasses, contain water uniformly throughout the glass. They are the result of equilibrium hydration of silicate melts at high pressures $[6,9,11]$. Diffuse reflectance was able to reproduce the ratios of water to hydroxyl, as measured by the ratio of the $5200 \mathrm{~cm}^{-1}$ absorption to that at $4500 \mathrm{~cm}^{-1}$ (Figure 3). The scatter in the diffuse reflectance data is qult te noticeable in comparison to the transmission data (both were run on the same machine). This scatter appears to be due to errors in baseline subtraction. Figure 4 shows a typical spectrum used for this test: the curvature of the background is due to instrumental factors (above $5000 \mathrm{~cm}^{-1}$ ) and the tail of the very intense infrared absorption (below $5000 \mathrm{~cm}^{-1}$ ). It is antictpated that the scatter may be eliminated by better baseline subtraction techniques, but we cannot rule out the possibility that there are small systematic differences in the relative intensities in diffuse reflectance and transmission work. Figure 3 indicates that errors of $\pm 20 \%$ in the $\mathrm{H}_{2} \mathrm{O} / \mathrm{OH}$ ratio are to be expected.

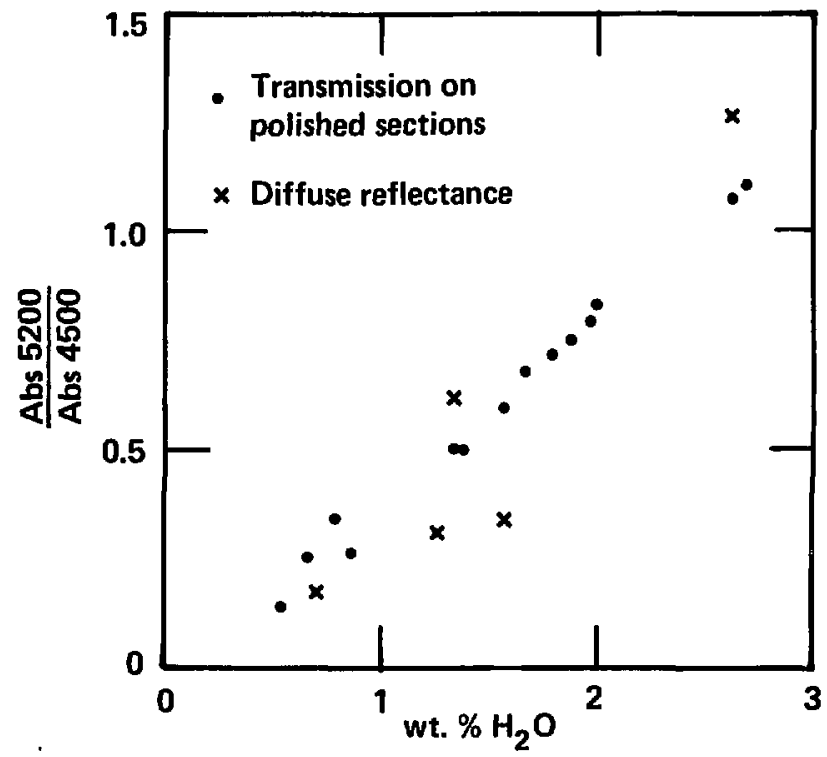

Figure 3. Comparison of peak ratios obtained from transmission spectroscopy [9] on natural hydrous obsidians, with that obtained from diffuse reflectance on samples from the same suite. Wt. $\% \mathrm{H}_{2} \mathrm{O}$ obtained by hydrogen manometry [9] is independent of both spectroscopic methods. 


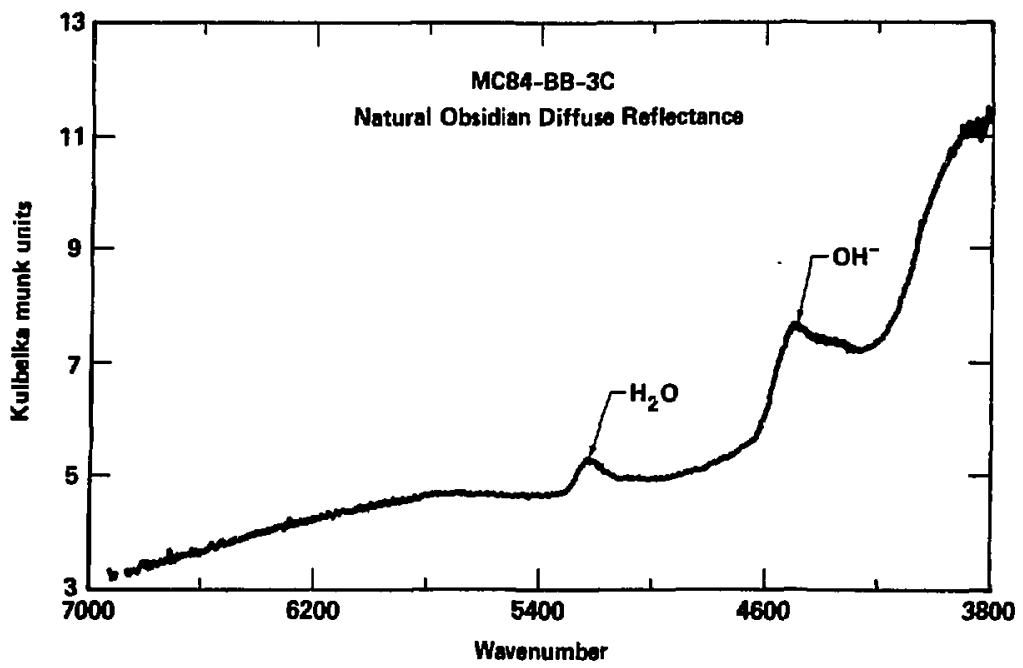

Figure 4. Diffuse reflectance spectrum of a natural hydrous obsidian sample containing $1.59 \%$ total $\mathrm{H}_{2} \mathrm{O}$, used in study [9]. One layer of 200-300 $\mu_{\text {m }}$ grains was used on a surface aluminized mirror, with the mitror as reference. Sample $\mathrm{MC}-\mathrm{BB}-3 \mathrm{C}$, [9].

\section{RESULTS}

SRL-13]_0lass. Two samples of hydrated SRL-131 glass were studied. The first was hydrated for 20 days at $202^{\circ} \mathrm{C}$ in a water vapor saturated atmosphere [12,13]. This resulted in a hydrated layer about $70 \mu^{m}$ in thickness. This layer was studied in cross section, along with the adjolning (visibly unaltered) glass. The near-infrared spectrum obtal ned is shown in F1gure 5. Molecular water (at 5200 $\mathrm{CII}^{-1}$ ) is the dominant hydrogen spectes in this layer; hydroxyl is considerably less intense at $4350 \mathrm{~cm}^{-1}$. The broader absorption seen in the ATM 1-C sample (Figure 1) for hydroxyl, from 4350-4500, indicates that hydroxyl environments are not 1dentlcal in these leached glasses. Molar absorptivities (Beer-Lambert law absorptivities) are not highiy varlable in natural hydrous glasses [9]. Therefore we can use the molar absorptivity values (as $\mathrm{H}_{2} \mathrm{O}$ ) determined by Newman et al. [9] to estimate the quantities of water and hydroxyl in this layer. Their value of $1.61(11$ fers $/ \mathrm{mol}-\mathrm{cm})$ yields 4.8 moles/1iter molecular water from the $5200 \mathrm{~cm}^{-1}$ absorption: for hydroxyl their value of 1.73

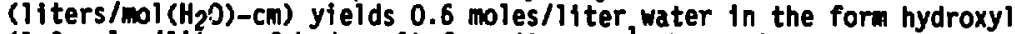
(1.2 moles/liter of hydroxyl) from $4350 \mathrm{~cm}-1$ absorption. The transition from the bulk glass to the hydrated layer is optically sharp in the visible region, and a similar result was seen in the infrared. No increase in water content is seen in the bulk glass (at a resolution of $35 \mu \mathrm{m})$ until the optically deternined layer is reached. The vater content of the unaltered glass could be determined from the absorption at $3500 \mathrm{~cm}^{-1}$. Using Newman et al.'s [9] value for hydroxide absorptlyity $\left(10011\right.$ ters $\left.\left./ \mathrm{mol}^{(} \mathrm{H}_{2} \mathrm{O}\right)-\mathrm{Cm}\right)$ yields a hydroxyl content of $1.07 \times 10^{-2}$ moles $\left(\mathrm{H}_{2} \mathrm{O}\right) / 1$ iter. 


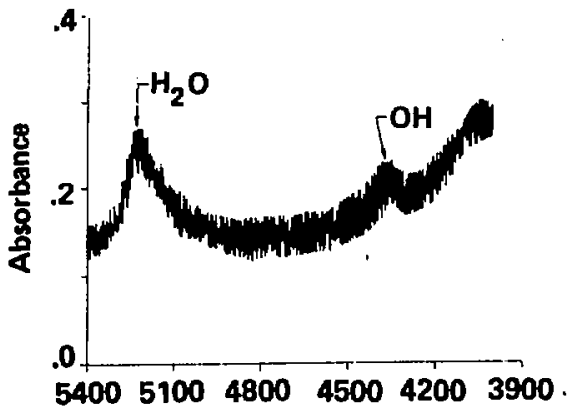

Wavenumber

Figure 5. Transmission near-infrared spectrum of hydrated layer on SRL-131 glass formed by vapor hydration, 20 days at $202^{\circ} \mathrm{C}[12]$. Layer observed in cross sectior: at center of layer, using 35 un aperture. sample $147 \mathrm{~mm}$ thick.

Infrared spectroscopic data only determine the number of absorbing species per unit volume. However, we can estimate the density of the hydrated layers to determine wt. I water. If the layer's density is 2.5 g/cc, the bulk glass contains less than $0.01 \approx \mathrm{H}_{2} \mathrm{O}$, and the hydrated layer contains about $3.5 \% \mathrm{H}_{2} \mathrm{O}$ as molecular water, and $0.4 \% \mathrm{H}_{2} \mathrm{O}$ as hydroxyl. The final result of vapor phase hydration was the addition of mostly molecular water to the glass.

$A$ second SRL-131 sample that had been leached in delonized water under $M C C-1$ conditions $\left(90^{\circ} \mathrm{C} S / \mathrm{V}=0.1 / \mathrm{cm}\right)$ for 182 days [14] was examined by removing the hydrated layer with \& razor blade. The layer flaked off easily. The transmission and diffuse reflectance mid-infrared spectra of this layer are stiown in Figure 2. An area of about $3 \operatorname{mm}^{2}$ was examined in this measurement. This sample was too thin to determine water/hydroxyl ratios from the near infrared bands at 5200 and 4350 $\mathrm{Cm}^{-}$. However, the $1600 \mathrm{~cm}^{-1}$ band may be used to determine water content, and the $3500 \mathrm{~cm}^{-1}$ band is proportional to the sum of water and hydroxyl. Again using Newman et al.' 's values [9], the $1600 \mathrm{~cm}^{-1}$ intensity indicates 1.5 moles/1iter nolecular water, and the $3500 \mathrm{~cm}^{-1}$ band indicates a total water content of about 2.13 moles/11ter as hydroxyl, taking into account the 1.5 moles/liter present as water determined from $1600 \mathrm{~cm}^{-1}$ absorption. The absorption intensity at $1600 \mathrm{~cm}^{-1}$ is a maximum value. There are typically minor absorptions from silicate overtones in this region $[4,6]$ which may be contributing to the intensity in this region, but no accurate baseline is avallable because of the possibility that the silicate overtones are different in the hydrated glass and the anhydrous glass.

SRL-165 Glass. A suite of glass wafer samples used for static leach testing by Bazan and Rego [15] and simflarly prepared unreacted samples were examined using diffuse reflectance. These samples were tested at temperatures of $90^{\circ} \mathrm{C}$ in DIM and $\mathrm{J}-13$ water and $\mathrm{S} / \mathrm{V}$ values ranging from 0.3 to $4 / \mathrm{cm}$; the extent of reaction was not large (less than $8.5 \mathrm{~g} / \mathrm{m}^{2}$ after 56 days in DIW) [15]. Only hydroxyl is detectable in these samples. Surfaces of unreacted wafers that had been sau-cut or 
polished in water showed absorption at $3500 \mathrm{~cm}^{-1}$, while those that were prepared equivalently but using Buehler $F M$ polishing oll showed no absorption. This indicates that initial hydration of the glass takes place during preparative procedures used for leach testing. The surface of one of these water-prepared wafers gave an absorption at $3500 \mathrm{~cm}^{-1}$ of 0.21 Kubelka-Munk units. After reaction for periods ranging from 14 days at $S A / V=0.5 / \mathrm{cm}$ to 56 days at $0.3 / \mathrm{cm}$, the absorbances ranged from 0.40 to 0.47 Kubelka Munk units. It appears that a significant amount of the total hydration occurred during sample preparation, and that the thickness of the hydrated layer changes only very slowly during leaching of this glass at elevated temperature. This confirms the smali extent of reaction determined by normalized ic;s [15] and SEM examination of the surfaces [14]. Because we have not calibrated the absolute reflectance values as a function of water content, $1 \mathrm{t}$ is not possible to determine the amount of water that is present in these layers, but it is all in the form hydroxyl.

ATM-ic Glass. ATM-ic is a PNL 76-68 based glass that was originally designed as a reference glass for commercial high-level waste [15]. He studied both powder and wafer samples that were reacted in DIW and $J-13$ water [F. Bazan and J. Rego, unpublished]. An infrared spectrum of the powdered glass reacted in DIW was shown in Flgure 1 . In these powders, the total water content increased as a function of reaction time in DIW (Figure 6). Inttially the added water was in the form hydroxyl ( 3 days at $S / V-4 / \mathrm{Cm}$, DIH at $90^{\circ} \mathrm{C}$ ). However, by 28 days, the water added to the glass, as determined from the absorptions in the Near Infrared (Figure 1), is predominantly molecular water with about $1 / 3$ of the total occurring as hydroxyl. Simtlar results were found for reacted wafers, al though these samples proved to be more difficult to study due to the relatively small surface area compared to the powders. In J-13 water (a silficate/carbonate ground water), however, there was no measurable addition of molecular water, and only a small (inx) increase in hydroxyl. This is in accord with the low reactivity of this glass in J-13 water.

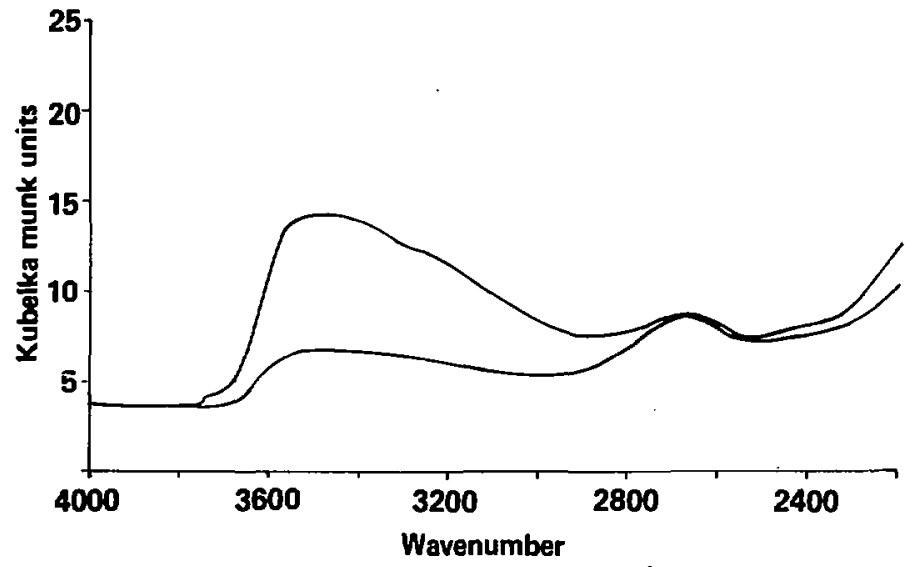

Figure 6. Diffuse reflectance spectra of two leached ATM-1C powders. Bottom ; 3 days, TCP; 28 days. SA/V $-4 / \mathrm{cm}$, DIW at $90^{\circ} \mathrm{C}$. Top is same sapple as in Figure 1 . 


\section{DISCUSSION}

\section{Previlous Hork}

Previous studies of the hydration process of glass have proceeded along two paths of inquiry. The first has examined the process of hydration layer formation, and the concomitant loss of alkali elements in those layers. The second approach has emphasized the study of water in melts, and the hydrous glasses quenched from them. These two approaches have yielded fundamentally different interpretations of the nature of hydrated glass, which must now be reconciled.

The hydrogen and alkali distribution in hydrated layers on glass was conclusively determined experimentally in a serles of studies using depth proflling technlques $[18,19,20]$. These studies supported the interdiffusion theory of hydration, which has become known as the Doremus model [e.g. 20, 21]. In this theory, hydration proceeds through the exchange of hydrogen or hydrontum lon from solution, for sodium cor other alkails) in the glass. Experimental determination of smooth diffusion profiles for both participants strongly supports this mechanism. In many alkali-silicate glasses, hydrogen replaces alkalis at a ratlo of three hydrogens to one alkall; however, other ratios as low as une are also found $[20,21]$. The depletion of sodium matches the increase in hydrogen as the layer forms, but the rate of hydration is found to be cntirely dependent on hydrogen, which has a diffuston coefficient 3 orders of magnitude smaller than sodium [20] and controls the rate of interdiffusion.

The interdiffusion mechanism replaces sodium with a hydrogen ion species. However, it is also well known that glasses can contain molecular water ([5,6,7,8] and this work). In silicate melts, it has been conclusively demonstrated $[6,11]$ that water, hydroxyl, and bridging oxygens exist in an equilibrlum described by:

$$
\mathrm{H}_{2} \mathrm{Omolecular}(m e l t)+0^{\circ}(\text { melt })-2 \mathrm{OH}(\text { melt })
$$

where $0^{0}$ refers to a bridging oxygen, and 0 H refers to an OH group attached to a sillcate polymer. The equilibrium constant for this equilibrium is:

$$
K=\frac{\left(a_{O H}^{m}\right)^{2}}{\left(a_{H 2 O, m o l}^{m}\right)\left(a_{0}^{m}\right)}
$$

where $\left.a^{m} H, a_{H 2 O}^{m}, m\right)$ and $a_{0}^{m}$ refer respectlvely to the activities of hydroxyl groups, molecular water, and bridging oxygens in the meit. This equilibrtum constant has been found to be equal to approximately $0.2[6,9,11]$. In a relatively siliceous melt $\left(\sim 40\right.$ to $\left.B 0 \% \mathrm{~S} 10_{2}\right)$, the initial "water" added in hydration goes in as hydroxide. The amount of molecular water increases until it is equal to hydroxide at about 2 z (by wt.) in typical natural melts. At higher water concentrations, hydroxyl addition slows dramatically (as all bridging oxygen sites are used) and additional water enters in the form molecular water [11].

Although the study of hydrogen speciation in silicate melts has been largely conducted on glasses quenched from those melts, there have also been equivalent studies of water solubility in glasses below their softening point $[5,7]$. In these studies, identical behavior to that 
described by equations (1) and (2) was observed. A notable study in this area was of the hydrogen speciation in colloidal silica gels as a function of heat treatment [B]. In this study, spectra which are nearly identical to those presented in this paper in both peak appearance and relative intensities were observed in pure silica gels, with initial water/hydroxyl ratios of about 2:1 decreasing as a function of temperature as the gels were gradually heated and dehydrated. Detailed assignments of spectral features to possible silica-water organizations are given. Although the equilibrium shown in (2) is not quantified in [8] for silica gel, the effects of the equilibrium are discussed in terms of structural changes in the gel. The very similar spectral characterization of silica gels, and hydrated glass layers, indicates they share some structural characteristics.

In summary, a number of excellent previous studies of the hydrated layers on alkali-silicate and nuclear waste glasses suggest that hydration occurs by alkalf-hydrogen interdiffusion $[1,3,18,19,20,21]$. At the same time, studies of the actual speciation of hydrogen in hydrated glasses, including this study, have shown that moiecular water is an important hydrogen species. This has not been previously demonstrated for nuclear waste glasses. The amount of molecular water increases relative to hydroxyl as a function of total water content in the SRL-131 and ATM 1-C glasses, and we infer that the absence of molecular water in the SRL-165 glasses is due to their Iimited extent of reaction, and hence hydration. There is experimental evidence that equations (1) and (2) apply to all hydrated glasses, and sound theoretical arguments may be made to that affect as well [11].

\section{Propertles of Hydrated Layers}

We believe that the experimental evidence presented and discussed here is consistent with a mechanism whereby nuclear waste glasses, and possibly other alkall sflicate glasses, hydrate by alkali-hydrogen interdiffusion. The hydrogen thus introduced into the very silica-rich outer layer then re-equilibrates, according to equations (1) and (2). Note that both these processes conserve charge within the hydrated layer. The actual diffusing specles in the alkali-hydrogen interdiffusion has been suggested to be hydronium Ion $[20,21]$ based on a frequently observed ratio of 3 hydrogens added for each alkall removed. However, this ratio is also frequently violated ranging as low as $1: 1$ in previous work [21]. In reference [2] the ratio is approximately $2: 1$. In the SRL-131 glasses in this study, the ratio is about $0.7: 1$ (considering only $\mathrm{Na}$ and $\mathrm{Li}$ ). Hydronium is not a common species in solids, and has only been identified as a stable species in crystalline hydrates of strong acids [4]. The spectroscopic evidence presented here may be adequately accounted for by a mixture of water and hydroxyl groups, in a very similar fashion to $[5,6,7,8]$. It is possible that hydronium is an intermediate species in the diffusion process, or that its spectroscopic manifestations are not distinct in this system. However, there is no direct evidence for its presence.

If hydronium ion were the diffusing species, it could yield a hydroxyl group and molecular water in the hydrated layer, implying a constant ratio of hydroxyl to water of $1: 1$. However, it is likely that the equilibrium of eqs. (1) and (2) would cause the water to react to form hydroxyl at low concentrations, wh.le at high concentrations hydroxyl would react to form water. If $\mathrm{K}=0.2$ in eq. (2), the crossover would occur at the point where $\mathrm{H}_{2} \mathrm{O}$ and $\mathrm{OH}^{-}$are at the same concentration at equilibrium, or about 3 to $4 \mathrm{H}_{2} \mathrm{O}$ by wt. [11]. This 
would result in a glass undergoing first hydrolysis, then condensation, of Si-O-Si linkages as a function of hydration. However, if all hydrogen is added as hydroxy? (1.e. the diffusing spectes is $\mathrm{H}^{+}$), then the inftial interdfffusion would result in a hydroxyl-rich layer, in which equilibrium according to (1) would be achieved by the reaction proceeding to the left, with precipitation of molecular water and a net condensation of the silicate framework. This condensation would occur for any value of the equilibrium constant $K$ in eq. (2), because there is no water initially in the glass and all hydrogen would be added in the form of hydroxyl. For values of $K$ stmilar to those observed in nature and in the high temperature $\left(>300^{\circ} \mathrm{C}\right)$ hydration of alkall silicate glass, (around 0.2 ), the number of Si-0-Si linkages would increase

substantialiy in this case. The exact number is equal to the number of water molecules, as presented in this paper (1.5 moles/liter in the MCC-1 leached SRL- $|3| \mathrm{g}$ !ass $\rangle$.

We do not currently have enough evidence to establish the nature of the interdiffusing species. It is possible that the overall hydrogen stoichiometry is intermedlate or variable. Detailed hydrogen profiling as in [2] must be comblned with IR spectroscopy to attempt to resolve this; samples will be frozen after hydration to prevent loss of water. However, the low ratio of hydrogen added to alkall removed precludes $\mathrm{H}_{3} \mathrm{O}^{+}$from being the dominant added species in the SRL glasses. The hydroxyl contents of the two SRL glasses are also nearly the same, despite the large difference in total water. This is predicted by the equilibration reaction (1); at high water contents, tile hydroxyl content changes very slowly relative to $\mathrm{H}_{2} \mathrm{O}[6,11]$. He conclude that hydronium ion $\left(\mathrm{H}_{3} \mathrm{O}^{+}\right)$is not required to explain our results.

Since silicate glasses and melts may be induced to hydrate at high temperatures and pressures without loss of alkalis, 1.e. by simple diffusion of water into the glass, it may be questioned whether that process occurs at a significant rate at the lower temperatures and pressures of interest here. This appears unlikely, due to the very low chemical diffusion coefficient for molecular water $[20,21,22]$. Even if initial hydration by simple diffusion occurs, hydration by interdiffusion would be 3 orders of magnitude more ranid. However, hydration in water vapor may not allow complete removal of alkalis, hindering interdiffusion and aiding simple diffuston. Also, simple diffusion may occur at a higher rate in glass already hydrated by interdiffusion.

The total water content (molecular and hydroxyl) of the nuclear waste glass layers in this study is not great, ranging up to $4 \%$ (by w.) in the vapor-hydrated sample. This value is approximate since it is calibrated only against natural hydrous glasses. Comparison of natural and man-made hydrous glasses $[6,9]$ suggests that molar absorptivities could vary by as much as 50\%, yielding maximum values of 2-6\% water by weight in our SRL-131 samples. A determination by weight loss in a similarly treated sample yielded about $7 \%$ welght loss [14]. In reference [2], a nuclear profiling study of a hydrated layer in SRL-165 glass yielded a total hydrogen content approximately equal to twice the original alkali content of the glass (on a per atom basis), equivalent to about $11 \mathrm{wt} \% \mathrm{H}_{2} \mathrm{O}$. (A total of about $6 \times 10^{-3}$ moles/gram alkalt, converted to half that number of moles $\mathrm{H}_{2} \mathrm{O}$ per gram.) Thus $1 \mathrm{t}$ does not appear that hydrated layers on nuclear waste glass contain the large amounts of water associated with a gel (20\% or greatei), and their densities should only be slightly less than that of the original glass. 


\section{CONCLUSIONS}

The hydrated outer layer of a leache-t nuclear waste glass contains substantial amounts of molecular water, up to several times as much water as hydroxy?. The amount of total water, and the ratio of water \pm 0 hydroxy1. increases as a function of reaction time. This process is consistent with the alkali-interdiffusion concept of glass hydration. followed by which the introduced hydrogen re-equilibrates with the silicate framework.

It is an interesting observation that PNL 76-58 glasses hydrate more slowly, and yet are less durable, than SRL-131 and 165 glasses $[13,14]$. The nature of the nydrated layer on the SRL glasses may be partly responsible for this difference. Because of the necessary condensation of the sillicate framework at high water contents regardless of the actual diffusing specles, "+ or $\mathrm{H}_{3} \mathrm{O}^{+}$, the hydrated layer on a waste glass may be more resistant to dissolution rather than less reststant, as has been commonly assumed.

\section{ACKNONLEDGNENTS}

We would like to thank Edward Stolper, California Institute of Technology, for allowing us to use the natural obsidian samples used in reference [9]. Th1s work was conducted under tine auspices of the U.S. Bepartment of Energy by the Lawrence Livermorg Hutional Laboratory under contract number $\mathrm{H}-7405-\mathrm{ENG}-48$, and as part of the Nevada Nuc? ear Waste Storage Investigations (NNHSI).

\section{REFERENCES}

1. J.E. Mendel, (compiler) Final Report of the Defense High Level Leaching Mechanisms Program, Paclftc Northwest Laboratory, Report PAL $5 ; 57$ (1984).

2. D.L. Phinney, F.J. Ryerson, V.M. Oversby, H.A. Lanford, R.D. Aines, and J.K. Bates, Integratid testing of the SRL waste form. This volume.

3. T.A. Abrajano and J.K. Gatos, Transport and Reaction Kinetics at the Gel: Glass Transition Zcne: Results of Repository-Oriented Experiments. This volume.

4. R.D. Aines and G.R. Rossman, Water in minerals? A peak in the Infrared. Journal of Geophysical Research 89, 4059-4071, (1984).

5. R.F. Eartholomew, B.L. Eutler, H.L. Hoover, C.K. Wu, Infra.red spectra of a watgr-containing glass. Journal of the American Ceramic Society $63,481-485$.

6. E. Stolper, Water in sillcate glasses: an infrared spectroscopic study. Contributions to Mineralogy and Petrology 리, 1-17 (1982).

7. O.R. holters and $H$. Verwels. The incorporation of water in silicate glasses. Physics and Chemistry of Glasses 22, 55-61 (1981).

B. D.L. Hood, E.M. Rabinovich, D.W. Johnson, Jr., J.B. MacChesney, E.M. Vogel, Preparation of high-sllica glasses from colloidal gels: III, Infrared spectrophotometric studies. Journal of the American Ceramic Society, 66, 693-699 (1983).

9. S. Newman, E.M. Stolper, S. Epsteln, Measurement of water in rhyolitic glasses: Calibratton of an infrared spectroscopic technique. Anerican Mineralogist, 71, 1527-1541 (1986).

10. R.N. Clark and T.L. Roush, Reflectance spectroscopy: Quantítative analysis for remote sensing applications. Journal of Geophysical Research 89, 6329-6340, (1984). 
11. E. Stolper, The speciation of water in silicate melts. Geochemica et Cosmochemica Acta 46, 2609-2620.

12. J.K. Bates, L.J. Jardine, M.J. Steindler, The Hydration Process of Nuclear waste Glass: An Interim Report. Argonne National Laboratory, Report ANL-82-11 (1982).

i3. F.E. Diebold and J.K. Bates, Glass-water vapor interaction. American Ceramic Society, Proceedings, 1986, in press.

14. J.K. Bates, unpublished.

15. F. Bazan, and J. Rego, Parametric Testing of a DWPF Glass. Lawrence Livermore National Laboratory, Report, UCRL 53606.

16. J.W. Hald, Fabrication and Characterization of MCC Approved Testing Material - ATM-1 Glass. Pactfic Northwest Laboratory, Battelle Memorial Institute, Report PNL-5577-1, (1985).

17. J.M. Delany, Reaction of Topopah Spring Tuff with J-13 Water: A Geochemical Modeling Approach Using the E03/6 Reaction Path Code. Lawrence Livermore National Laboratory. Report UCRL-53631, (1985).

18. I.S.T. Tsong, C.A. Houser, S.S.C. Tong, Depth profiles of interdiffusing species in hydrated glasses. Physics and Chemistry of Glasses 21, 197-198, (1980).

19. C.A. Houser, J.S. Herman, I.S.T. Tsong, W.B. White, W.A. Lar foró, Sodium-hydrogen interdiffusion in sodium silicate glasses. Journal of Non-Crystalline Solids 4l, 89-98 (i980).

20. H.A. Lanford, K. Davis, P. Lamarche, R. Groleau, R.H. Doremus, Hydration of soda-lime glass. Journai of Non-Crystalline Solids $33,249-265$ (1979).

2i. R.H. Doremus, Diffusion-controlled reaction of water with glass. Journal of Non-Crystalline Solids 55, 143-147 (1983).

22. M. Nogami, and M. Tonazawa, Diffusion of water in high silica glasses at low temperature. Physics and Chemistry of Glasses 25. 82-85 (1984).

\section{DISCLAIMER}

This report was prepared as an account of work sponsored by an agency of the United States Government. Neither the United State, Government nor any agency thereor, nor any of their employes, makes any warranty, express or implied, or assumes any legal liability or responsibility for the accuracy, completeness, or usefulness of any information, apparatus, produch, or process disclosed, or represents that its use would not infringe privately owned rights. Reference herein to any specific commercial product, process, or service by trade name, trademark, manufacturer, or otherwise does not necessarily const' - it or imply its endorsement, recommendation, or favoring by the United States Government or any agency thereof. The views and opiniuns of authors expressed herein do not necessarily state or reflect those of the Uniled States Government or any agency thereor. 